\title{
MINDFULNESS NAS TERAPIAS DE REDUÇÃO DA ANSIEDADE
}

\author{
Amanda Flávia Gonçalves Lima ${ }^{1}$ \\ Arthur Siqueira de Sene ${ }^{2}$
}

\section{RESUMO}

INTRODUÇÃO: As terapias fundamentadas no mindfulness têm o objetivo de modificar a maneira pela qual o indivíduo estabelece a sua relação com os seus pensamentos que pode gerar ansiedade, de forma a contribuir para o indivíduo aprender a focalizar a atenção no exato instante da sua vivencia, percebendo quais sensações que aparecem no corpo ao sentir a ansiedade. OBJETIVO: Abordar os benefícios da mindfulness no auxílio do tratamento de transtornos de ansiedade. METODOLOGIA: A presente pesquisa foi realizada por meio de uma revisão seletiva da literatura, de natureza qualitativa e descritiva. Foram consultadas bases de dados como SCIELO, LILACS e BIREME além de livros, teses e monografias de diversas instituições de Ensino Superior. PUBLICADOS prioritariamente em língua portuguesa no período de 2004 a 2017. RESULTADOS: O mindfulness é um ponto de encontro entre várias intervenções clínicas, que envolve a autorregulação da experiência imediata a fim de uma recognição dos acontecimentos, trata-se de uma orientação de abertura e aceitação das experiências momento a momento. Este modelo, visa possibilitar a capacidade de atenção para observar as experiências para aceita-las livre dos julgamentos que surjam na consciência. O mindfulness proporciona mudanças significativas a nível psicofisiológico e mais rapidez na recuperação após uma provocação negativa, diminuindo a ansiedade, e aumentando o afeto positivo. A prática do mindfulness está integrada a mudanças funcionais transitórias, estruturais na plasticidade cortical e uma possível mudança de característica, pois muda a maneira como o indivíduo percebe os acontecimentos a sua volta. A meditação mindfulness tem em comum com a terapia cognitiva a ideia de que a percepção e o pensamento direcionam a emoção e o comportamento. Dessa forma, se o

\footnotetext{
${ }^{1}$ Acadêmica do curso de psicologia da Faculdade Patos de Minas - FPM. E-mail de contato: amandaflavia14@hotmail.com ${ }^{2}$ Docente do departamento de psicologia da Faculdade Patos de Minas - FPM. E-mail de contato: arthurssene@gmail.com
} 
indivíduo for capaz de mudar sua relação com os próprios pensamentos, ele pode alterar padrões de comportamento autodestrutivos profundamente enraizados. A base de evidências que suportam a eficácia dessa terapia é menos robusta que no caso da Terapia Comportamental tradicional, por ser uma terapia mais recente, porém trata-se de intervenções promissoras para ajudar a elucidar o processo de mudança e oferecer estratégias complementares para ajudar os pacientes. CONSIDERAÇÕES FINAIS: Os estudos utilizados apontam que as estratégias do mindfulness permitem ensinar o paciente a lidar com os desafios da vida, focando intencionalmente a sua atenção na vivência imediata, ao passo que reduz a ansiedade e potencializa o afeto positivo. Trata-se de um método não farmacológico eficaz de tratamento da ansiedade que pode prevenir futuros episódios de ansiedade, representando também um modelo eficaz de prevenção.

Palavras chave: Mindfulness; Terapia Cognitiva Comportamental; Transtornos de ansiedade. 